\title{
The magnitude and impact of the 431 CE Tierra Blanca Joven eruption of Ilopango, El Salvador
}

Smith, V.C. ${ }^{1^{*}}$, Costa, A. ${ }^{2^{*}}$, Aguirre-Díaz, G. ${ }^{3}$, Pedrazzi, D. ${ }^{4}$, Scifo, A. ${ }^{5}$, Plunkett, G. ${ }^{6}$, Poret, M. ${ }^{7}$, Tournigand, P.Y. ${ }^{8}$, Miles, D. ${ }^{1}$, Dee, M. ${ }^{5}$, McConnell, J.R. ${ }^{9}$, Sunyé-Puchol, I. ${ }^{3,1}$, Dávila Harris, P. ${ }^{10}$, Sigl., M. ${ }^{11}$, Pilcher, J.R. ${ }^{6}$, Chellman, N. ${ }^{9}$, Gutiérrez, E. ${ }^{12}$

1. Research Laboratory for Archaeology and the History of Art, School of Archaeology, University of Oxford, Oxford OX1 3TG, UK. *victoria.smith@arch.ox.ac.uk https://orcid.org/0000-0003-0878-5060

2. Istituto Nazionale di Geofisica e Vulcanologia, Bologna 40128, Italy. *antonio.costa@ingv.it https://orcid.org/0000-0002-4987-6471

3. Centro de Geociencias, Universidad Nacional Autónoma de México, Querétaro 76230, Mexico.

4. ICTJA, CSIC, Group of Volcanology, SIMGEO UB-CSIC, Institute of Earth Sciences Jaume Almera, Lluis Sole i Sabaris s/n, 08028 Barcelona, Spain

5. Centre for Isotope Research, University of Groningen, Groningen 9747 AG, the Netherlands.

6. Archaeology \& Palaeoecology, School of Natural and Built Environment, Queen's University Belfast, Belfast BT7 1NN, Northern Ireland, UK

7. Laboratoire Magmas et Volcans, Université Clermont Auvergne, CNRS, IRD, OPGC, ClermontFerrand, France.

8. Dipartimento di Geoscienze, Università degli studi di Padova, 35131 Padua, Italy

9. Desert Research Institute, Reno, Nevada 89512, USA

10. División de Geociencias Aplicadas, Instituto Potosino de Investigación Científica y Tecnológica, San Luis Potosí 78216, Mexico.

11. Climate and Environmental Physics Physics \& Oeschger Centre for Climate Change Research, University of Bern, Sidlerstrasse 5, 3012 Bern, Switzerland

12. Gerencia de Geología del Observatorio Ambiental, Ministerio de Medio Ambiente y Recursos Naturales, San Salvador 76230, El Salvador

Corresponding authors:

victoria.smith@arch.ox.ac.uk; antonio.costa@ingv.it

PDF includes:

Main text: $~ 5248$ words and 59 references

4 Figures

2 Tables

Supporting Information

Classification

Physical Sciences; Earth, Atmospheric, and Planetary Sciences

\section{Keywords}

Maya; large volcanic eruptions; sulfate; eruption dispersal; ice cores; radiocarbon 


\begin{abstract}
The Tierra Blanca Joven (TBJ) eruption from llopango volcano deposited thick ash over much of El Salvador when it was inhabited by the Maya, and rendered all areas within at least $80 \mathrm{~km}$ of the volcano uninhabitable for years to decades after the eruption. Nonetheless the more widespread environmental and climatic impacts of this large eruption are not well known because the eruption magnitude and date are not well constrained. In this multifaceted study we have: resolved the date of the eruption to $431 \pm 2$ CE by identifying the ash layer in a well dated, high-resolution Greenland ice core record that is $>7,000 \mathrm{~km}$ from Ilopango; and calculated that between 37 and $82 \mathrm{~km}^{3}$ of magma was dispersed from an eruption coignimbrite column that rose to $\sim 45 \mathrm{~km}$ by modeling the deposit thickness using state-of-the-art tephra dispersal methods. Sulfate records from an array of ice cores suggest stratospheric injection of $14 \pm 2 \mathrm{TgS}$ associated with the TBJ eruption, exceeding those of the historic eruption of Pinatubo in 1991. Based on these estimates it is likely that the TBJ eruption produced a cooling of around $0.5^{\circ} \mathrm{C}$ for a few years after the eruption. The modeled dispersal and higher sulfate concentrations recorded in Antarctic ice cores imply that the cooling would have been more pronounced in the Southern Hemisphere. The new date confirms the eruption occurred within the Early Classic phase when Maya expanded across the Central America suggesting that the impact on the wider Maya population was limited.
\end{abstract}

\title{
Significance statement
}

The TBJ eruption of llopango occurred during Maya times but the exact timing and its impact has been controversial. It was thought to be responsible for the anomalously cold decade experienced in the Northern Hemisphere centered at $540 \mathrm{CE}$, but this date is at odds with archeological evidence that suggests a date near the start of the Early Classic period (pre-450 CE). Our precise age of $431 \pm 2$ CE allows us to pinpoint the eruption in proxy records and shows that its impact was apparently limited. It appears to have only had major effects on populations within $\sim 80 \mathrm{~km}$ of the volcano, where the regions were blanketed by decimeters of ash fallout and pyroclastic density currents.

\section{Introduction}

There have only been two large magnitude volcanic eruptions in the last two hundred years (erupted $>10 \mathrm{~km}^{3}$ of magma; VEI>=6) (1) for which we have well documented records of the impact. Like wildfires, tropical cyclones, tsunamis, and earthquakes, volcanic eruptions result in catastrophic local to regional impacts. However, one thing that sets eruptions apart from other natural hazards is the potential for more widespread effects associated with the injection of aerosols, especially sulfate, into the upper atmosphere. Sulfate aerosols that reach the stratosphere increase albedo and result in decreases in temperature at the Earth's surface on the hemispheric to global scale (2). After the 1991 Pinatubo (Philippines) eruption there was decline of up to $1^{\circ} \mathrm{C}$ in the sub-tropical troposphere (3) and following the $1815 \mathrm{CE}$ eruption of Tambora (Indonesia), cooler summers were experienced in North America and Europe. These cooler temperatures in 1816-1818 CE resulted in reduced growing seasons and poor harvests, which led to famine and high mortality across Europe and North America $(4,5)$. The impact of these eruptions is clear as they are comparatively recent and well documented, but evaluating the impact of similarly large eruptions further back in time is more difficult as written accounts often do not exist and there are large uncertainties in calculating the magnitude of the eruption and the amount of sulfate aerosols released. One way to establish the impact on climate and 
society is to use paleoenvironmental and archeological records, but this relies on identifying the eruption deposits within them, or obtaining a precise date for the eruption, so it can be pinpointed in records to evaluate its timing relative to climate and cultural variations.

Large regions of El Salvador and its Maya sites were covered by thick deposits from an eruption that occurred during the Early Classic Period, which lasted from 300 to 600 CE (6-8). The eruption that generated these deposits is named the Tierra Blanca Joven (TBJ) after its prominent outcrops of 'young white earth'. The eruption occurred from the llopango caldera a 13 by $17 \mathrm{~km}$ collapse structure formed and modified by its numerous large eruptions in the last $1.8 \mathrm{Ma}(9,10)$. The thickness of the deposits around the vent testifies to a large magnitude event, and such eruptions release sulfur into the stratosphere that converts into sulfate. This stratospheric sulfate gradually falls out, forming a deposit that can be detected in the polar ice cores $(11,12)$. There are a couple of large non-sea salt sulfur (nssS) peaks in ice core records retrieved from both polar ice-sheets, which are consistent with a tropical eruption that injected volatiles into both hemispheres, in 540 CE (13). Given that this falls within the range of radiocarbon dates for the TBJ eruption (270-562 CE; 95.4\% probability), the date of the eruption was pinpointed to the ice core nssS spike at 540 CE (14). However, the published radiocarbon measurements (quoted above) are particularly poorly constrained as they correspond with a plateau in the radiocarbon calibration curve, and there are other earlier nssS peaks that could have been generated by the TBJ eruption. The suggestion that the eruption occurred at $540 \mathrm{CE}(14)$ is controversial as archaeologists working in the region recovered some artefacts that were clearly influenced by Teotihuacan Culture from beneath the TBJ ash in the Tazumal and Casa Blanca archeological sites in Chalchuapa, 75 km NNW of Ilopango (Fig. 1). These Teotihuacan items are typical of those made at the start of the Early Classic Period (7) and hence, imply the eruption occurred prior to $450 \mathrm{CE}$. Furthermore, Maya ceramic assemblages recovered from archeological sites in El Salvador are similar to those found elsewhere in the region, but after about $400 \mathrm{CE}$ it appears that ceramic production ceased in $\mathrm{EI}$ Salvador for a period of around 100-150 years (15).

We examined both the regional and more widespread impact of the TBJ eruption via a multifaceted study. We have bought together a range of methods to assess the magnitude of the eruption and height of the eruption plumes. In order to pinpoint the eruption in paleoenvironmental records we also reassessed the date of the eruption by wiggle-matching radiocarbon measurements of successive tree rings onto the radiocarbon calibration curve. This improved date then provided constraints for us refine its date using a high-resolution polar ice core and its precise chronology (16). Our date also allows us to define the timing of the eruption within cultural and climate records, which can be used to assess how this eruption affected the region.

\section{The Tierra Blanca Joven eruption}

The TBJ deposits provide evidence that the eruption produced eruption plumes and fueled numerous pyroclastic density currents (PDCs) $(17,18)$. The first two eruptive phases were predominantly magmatic fallout with minor hydromagmatic activity, and these were followed by a sequence of PDC units (19), which deposited from dense to dilute currents. These deposits extend out $50 \mathrm{~km}$ from the vent (Fig. 1) and are up to $70 \mathrm{~m}$ thick in valleys near the caldera. Pedrazzi et al. (19) estimated the volume of the PDCs deposits to be at least $13 \mathrm{~km}^{3}$ dense rock equivalent (DRE). The PDCs generated a high co-ignimbrite (co-PDC) phoenix plume that 
generated the widespread dispersal of the volcanic ash over Guatemala, Honduras, Nicaragua, Costa Rica, and the Pacific Ocean (19).

\section{Magnitude and dispersal of the TBJ eruption}

The deposit thicknesses at more than 72 locations (data from ref. 19 and 20; see Methods) were used in order to produce a 3D numerical model (FALL3D) (21) reconstructing tephra dispersal from the co-ignimbrite phase and estimating the associated eruption parameters following the method proposed by Costa et al. $(22,23)$. This 3D approach uses: a set of timedependent meteorological fields from across the region, which were obtained from the European Centre for Medium-Range Weather Forecasts global atmospheric reanalysis (ERAInterim); a range of volcanological input parameters that include total erupted mass, mass eruption rate, column height, and total grain size distribution; and several hundred simulations of the FALL3D tephra dispersal model $(21,24)$. Further details of the modeling inversion and the use of the input parameters in FALL3D are detailed in recent studies (25). The range of volcanological input parameters used within the models were based on those estimated in the analytical model of Pedrazzi et al. (19) for the TBJ deposits. The FALL3D code is based on the numerical solution of a set of advection-diffusion-sedimentation equations coupled to a model that describes the density-driven transport responsible for the radial growth of the volcanic cloud at the neutral buoyancy level (24). The optimal eruption parameter values are obtained by producing best fits to measured TBJ deposit thicknesses across the dispersal area (shown in Fig. 1). These simulated results are in general agreement with the measured thicknesses, with most of the simulated thicknesses typically between 1/5 and 5 times those observed (see Fig. S1).

The FALL3D model results indicate approximately $55 \mathrm{~km}^{3}$ DRE was dispersed from the turbulent co-ignimbrite plume that rose to a height of $45 \mathrm{~km}$, with around $34 \mathrm{~km}^{3}$ DRE of material released into the stratosphere. The mean error associated to the estimation of the erupted mass is about a factor 1.5, which indicate the volume of magma dispersed by the plume was between 37 and $82 \mathrm{~km}^{3}$ DRE, and the maximum error a factor 3 (see SI Appendix). The fallout associated with this enormous and unstable plume resulted in around 2 million $\mathrm{km}^{2}$ being covered by more than $0.5 \mathrm{~cm}$ of ash within a few days (see SI movie). Adding the volumes of the PDCs $\left(13 \mathrm{~km}^{3}\right)$ (19) takes the total volume of magma erupted during the TBJ eruption to between 50 and $95 \mathrm{~km}^{3}$ DRE.

\section{Radiocarbon measurements and Bayesian age modeling}

In order to determine the date of the eruption we looked for organic material within the TBJ deposits to radiocarbon date. A slightly charred tree was found in late PDC deposits of the TBJ eruption at a location around $25 \mathrm{~km}$ NNW from llopango. The bark of the Mahogany tree (family Meliaceae) stump was intact and a cross section through the stump revealed up to 37 growth rings. Samples for radiocarbon dating were taken from packets of these rings, representing approximately 10 years, along two sections that extended out from the pith to the bark edge of the stump. The radiocarbon measurements of these samples were performed using a state-of-the-art Micadas Accelerator Mass Spectrometer at the University of Groningen, and these incredibly precise ${ }^{14} \mathrm{C}$ measurements were wiggle-matched onto the IntCal13 calibration curve (26) using a Bayesian statistical model ( $D$ _Sequence in OxCal) (27) to establish the date on which the tree was incorporated into the TBJ PDC (Table 1). These bark edge dates from each section where then merged in a separate OxCal model (Combine function), and 
indicate the TBJ eruption occurred between 425 and 440 CE (95.4\% probability; Fig. 2). This is a significant improvement on previous radiocarbon determinations for the eruption, which span 270 to 562 CE (95.4\% probability).

Radiocarbon dates from other trees in the TBJ deposits were recently published (14). They dated cross-sections from three tree stumps and similarly modeled these onto a radiocarbon calibration curve using Bayesian statistics. However, the authors used a mixed radiocarbon calibration curve, which combines the Southern Hemisphere SHCal13 (29) and Northern Hemisphere IntCal13 (26) datasets to calibrate the radiocarbon measurements and obtained calendar dates of $435-562$ CE (95.4\% probability) for two of the stumps. Their third stump (EI Mico A) produced an older age that sits just outside the range of the other two and because it was particularly decomposed, they suggest that it was dead prior to being incorporated into the flow (14). The justification for using a mixed calibration, 69\% Northern Hemisphere and 31\% Southern Hemisphere, curve was the tropical location of these trees (14), but llopango is at $13.8^{\circ} \mathrm{N}$ and clearly sits within a main Northern Hemisphere ${ }^{14} \mathrm{C}$ zone (30). Furthermore, recent studies suggest air masses over El Salvador come from Northern Hemisphere in both the austral summer and winter (31), which is also shown by the TBJ dispersal (Fig. 1). If the Dull et al. (14) data are calibrated using the accepted IntCal13 curve, the range of dates are slightly older than those reported in their paper, with one mode at 401-431 CE and another at 471-530 CE (95.4\% probability; SI Appendix). The older age range is consistent with our new radiocarbon data.

\section{Identifying the TBJ in the polar ice cores}

Within the timeframe established by the wiggle-match radiocarbon date (425-440 CE; 95.4\% probability) there is an apparently contemporaneous nssS spike in various Antarctic and Greenland ice cores (Fig. 3). Continuous measurements of the TUNU2013 ice core from northeast Greenland reveal an increase in particles at 431 CE (depth of 194.395 to $194.48 \mathrm{~m}$ on the master age-depth scale; Fig. 3) followed by a spike in nssS of up to $\sim 90 \mathrm{ppb}(\mu \mathrm{g} / \mathrm{g})$ at 433 CE. Absolute age uncertainties at this depth are estimated to be better than \pm 2 years $(13,33)$. The offset in particle and nss deposition is consistent with what is observed and modeled for volcanic eruptions, as it takes some time before the nssS is removed from the stratosphere (32, 34). For example, nssS was deposited a few months to a couple of years after the $1815 \mathrm{CE}$ Tambora eruption (35).

Approximately 14-15 volcanic glass shards were identified in the particle-rich TUNU2013 ice sample at $431 \mathrm{CE}$. Some of these shards had areas that were large enough to be analyzed. The major element compositions of these glass shards entirely overlap with those of the TBJ (Fig. 4; Table 2), and one of the ice core glass shards plots with the less evolved melt erupted during the TBJ eruption, confirming that these shards are distal TBJ ash that travelled $7,750 \mathrm{~km}$. It is not unusual for tephra to travel such distances (23) as other tephra layers identified in Greenland have been correlated to sources up to $8,000 \mathrm{~km}$ away $(36,37)$. This correlation provides additional confidence that the age of the TBJ eruption is $431 \mathrm{CE}$.

\section{DISCUSSION}

\section{Climatic and environmental impact of the eruption}

Multiple annually dated ice-core chronologies suggest that the large nssS spikes at around 433 CE in the Antarctic and Greenland ice cores are contemporaneous $(13,38)$. The TBJ glass shards in Greenland confirm that its nssS peak is associated with the TBJ eruption, and although the 
contemporaneous Antarctic peak could potentially be associated with another volcanic event there are aspects that suggest that is likely to be related to the TBJ eruption. Sulfur isotope measurements on samples encompassing the corresponding $433 \mathrm{CE}$ peak in another ice core from Antarctica show mass independent fractionation $\left(\Delta^{33} S=0.54 \pm 0.12 \%\right.$ ), which is consistent with sulfate aerosol formation in the stratosphere (39). The broad peak of volcanic sulfur concentrations, spanning more than 2 years in high-resolution ice-core records from Antarctica $(38,40)$, is consistent with a distal, low latitude source. Given this evidence and that other large magnitude eruptions from the low latitudes typically deposit sulfur at both poles (38) we consider that the Antarctic nssS peak at 433 CE is associated with the TBJ eruption. Extending tephra analyses to ice-cores from Antarctica offers a prospective to potentially test this attribution in the future. The 433 CE nssS concentrations in ice cores distributed over Greenland are variable, ranging from $40 \mathrm{ppb}$ to $80 \mathrm{ppb}$, and the highest concentrations recorded in Antarctica are around $60 \mathrm{ppb}$ (Fig. 3). Based on these ice nssS deposits, the TBJ eruption generated one of twenty highest volcanic stratospheric sulfur injections (14 $\pm 2 \mathrm{Tg})$ in the Common Era (33). Analysis of the Common Era ice core dataset shows that these large tropical eruptions result in $0.6 \pm 0.2{ }^{\circ} \mathrm{C}$ cooler temperatures in the northern hemisphere extratropics from June to August for at least four years after the eruption and often not recovering to pre-eruption values until 9 years after the eruption (13). More recent work has, however, suggested that the apparent decadal persistency in the reconstructed cooling may be biased from a biological memory in the tree-ring widths data included in the temperature reconstructions $(41,42)$. The $433 \mathrm{CE}$ ice-core records indicate an asymmetric stratospheric sulfur burden favoring the Southern Hemisphere (Fig. 3) (13). In addition to latitude, the hemispheric partitioning of sulfate aerosols following tropical eruptions depends on a variety of parameters most notably the Quasi-biennial oscillation that displays considerable seasonal variation $(43,44)$. There are large low latitude eruptions (e.g., Samalas 1257 CE and Krakatoa $1883 \mathrm{CE}$ ) that dispersed more sulfur in the opposing hemisphere (33) highlighting that sulfur transport is very dependent on the atmospheric circulation. Since the sulfur associated with the TBJ eruption was predominately dispersed into the Southern Hemisphere it is likely the cooling would have been significantly stronger there, with $0.5-1{ }^{\circ} \mathrm{C}$ cooler seasons for a few years after the eruption. Unfortunately, there are too few well-dated paleoclimate proxy records for the Southern Hemisphere to verify the climatic effect of the eruption (45).

It is difficult to establish the scale and the duration of the climate change around llopango and Central American regions following the eruption as few climate records have been sampled at sufficiently high resolution across this interval (46), with the sensitive proxies only typically being analyzed at intervals spanning 20 years (47). A regional $\delta^{18} \mathrm{O}$ record of a speleothem shows that rainfall in Central America has been particularly variable over the preceding millennia. It indicates that a period of relatively high rainfall started around 440 CE (7 and references therein) and extended for around 50-60 years, much longer than expected if it was purely volcanically-forced. Furthermore, the wet period is similar in magnitude and duration to others in the record that do not coincide with large volcanic events. In summary, data from proxy records in the region does not reveal any pronounced or long-term climate perturbation around the time of the eruption. However, it is possible that there was significant short-term change that has not yet been deciphered in these past environmental records as they have not been analyzed at a sub-decadal resolution. 
The input of the TBJ ash into the Pacific Ocean would have altered the ocean chemistry and effected biogeochemical cycles especially because the region of the Pacific Ocean south of El Salvador is particularly low in iron and chlorophyll (48). The TBJ ash has similar iron contents ( 1 wt\% FeO; Table 2) to that erupted by Pinatubo (Philippines) in 1991 (49) and similarly, Pinatubo deposited ash into a Fe-limited region of the ocean. The input from the 1991 Pinatubo eruption has been attributed to $\mathrm{CO}_{2}$-drawdown and increase in oxygen (50). Given that the TBJ eruption was an order of magnitude greater (total volume $50-95 \mathrm{~km}^{3}$ DRE) than the Pinatubo eruption (3-5 $\mathrm{km}^{3} \mathrm{DRE}$ ) it is likely there was a significant change in both atmospheric $\mathrm{CO}_{2}$ and $\mathrm{O}$ in the years following the TBJ eruption.

The dispersal of the tephra and distribution of the PDC deposits indicates that areas within 80 $\mathrm{km}$ of the vent were covered with decimeters of ash. Everything within these regions would have been destroyed and vegetation would have taken many years to decades to recover (23, 51). Further afield, in the Maya lowlands located more than $450 \mathrm{~km}$ from llopango where only millimeters of ash would have been deposited the effects appear to have been limited in this tropical environment, with archeological records suggesting that at the time the number of Maya monuments were increasing along with the population (7).

\section{Conclusions}

The co-ignimbrite (co-PDC) plume generated by the VEI6, Magnitude 7.1 TBJ eruption from llopango volcano dispersed between 37 and $82 \mathrm{~km}^{3}$ DRE of tephra over large areas of central America, with the very finest fraction travelling $>7,000 \mathrm{~km}$ to Greenland. Compositionally identifying the tephra in the ice core provides the precise date of $431 \pm 2$ CE for the eruption. This conclusive date is earlier than some other studies have suggested (14) but is consistent with all published data from the region. The position of the tephra in the Greenland ice core is associated with a slightly later peak in nssS, and a broad nssS peak linked to a low latitude eruption is observed at the same time in Antarctic ice cores. The coincident spikes in nssS suggest that this tropical eruption injected $\sim 14 \mathrm{Tg}$ of sulfur into the stratosphere which subsequently dispersed in both hemispheres. This injection into the upper atmosphere occurred during the later phases of the eruption when the particularly turbulent and unstable co-ignimbrite plume extended to a height of $45 \mathrm{~km}$. The local to regional impacts appear to have been restricted to areas within a few hundred kilometers of the vent, with no compelling evidence in paleoenvironmental records or historical accounts for significant impact at this time.

\section{Methods}

Ash dispersal modeling: Ash dispersal associated with the TBJ tephra deposits was simulated using the FALL3D model, which solves equations for advection, diffusion and sedimentation of particles (21) and accounts for gravity spreading of the umbrella region (24). The isopach maps were generated by modeling the tephra deposition in terms of mass loading $\left(\mathrm{kg} / \mathrm{m}^{2}\right)$ and converting to thicknesses, using a bulk density of $1,000 \mathrm{~kg} / \mathrm{m}^{3}$; following an approach that has been used for other eruption deposits $(22,23)$. The thickness measurements used in the FALL3D model are those from Pedrazzi et al., (19), and we included an additional two points where $3 \mathrm{~cm}$ of ash was recorded in cores: OC001 at $92.164417^{\circ} \mathrm{W}, 14.539192^{\circ} \mathrm{N}$, and MES001 at $92.136236^{\circ} \mathrm{W}, 14.477268^{\circ} \mathrm{N}(20)$. 
The input parameters required for the dispersal model include: mass eruption rate, eruption duration, eruption column height, mass distribution along the column, total grain-size distribution, and meteorological fields across the computational domain. As there is no direct way to estimate all these parameters at the time of the eruption, they were estimated by the model by minimizing the difference between observed and modeled thickness $(23,52)$ :

$K=\exp \left[\frac{1}{N} \sum_{i}^{N} \log \left(\frac{T_{i}(\text { obs })}{T_{i}(\text { calc })}\right)\right] ; k=\exp \left[\sqrt{\frac{1}{N} \sum_{i}^{N} \log \left(\frac{T_{i}(\text { obs })}{T_{i}(\text { calc })}\right)^{2}-\left(\frac{1}{N} \sum_{i}^{N} \log \left(\frac{T_{i}(\text { obs })}{T_{i}(\text { calc })}\right)^{2}\right.}\right]$

where $N$ is the number of data points (sample localities), $T_{i}(o b s)$ and $T_{i}$ (calc) represent the observed and calculated thicknesses, respectively, $K$ and $k$ are the statistical indexes (i.e. geometric average of the distribution and geometric standard deviation of the distribution), introduced by Aida (53).

The model assumes ash was injected into the atmosphere from vertically distributed point sources above the caldera. The TGSD of the co-ignimbrite deposits (19) was used for the simulations. The model accounts for the aggregation of fine ash using a parameterization (54), which assumes $50 \%$ of the $63-44 \mu \mathrm{m}$ ash, $75 \%$ of the $44-31 \mu \mathrm{m}$ ash, and $95 \%$ of the ash $<31$ $\mu \mathrm{m}$ fell as aggregated particles, with an effective diameter of $200 \mu \mathrm{m}$ (55). The effective density of these aggregates was found to be very low $\left(45 \mathrm{~kg} / \mathrm{m}^{3}\right)$ (19). The other parameters used in the model and the explored ranges are reported in Table S1. The simulations were carried out using a horizontal resolution of $\sim 20 \mathrm{~km}$ and a vertical resolution of $2 \mathrm{~km}$.

The reconstruction represents ash dispersal fed by the TBJ co-ignimbrite plume. However, this best-fit solution is not necessarily unique as there are a wide range of eruption source parameter combinations, the input parameters are inter-dependent, and not all computational settings were fully explored (e.g., 52, 56).

TUNU2013 ice core chronology: The 212 m-long TUNU2013 ice core was drilled in 2013 in northeast Greenland ( $78.04^{\circ} \mathrm{N}, 33.88^{\circ} \mathrm{W} ; 2105 \mathrm{~m}$ above sea level). The TUNU2013 ice core chronology is based on counts of the annual layers counted between fixed volcanic constraints using non-sea-salt sulfur signals to other Greenland ice cores, with the 774/5 CE cosmogenic event being the nearest calendar-dated fix point (13). This TUNU2013 chronology is within \pm 2 years of the North Greenland Eemian Ice Drilling (NEEM) project (NEEM-2011-S1) ice core timescale (13) and with the independent North Greenland Ice Core (NGRIP) project DRI-NGRIP2 ice-core timescale (57). The particle concentrations and compositional data along the core were determined by analyzing a stream of water obtained by continuously melting a $33 \times 33 \mathrm{~mm}$ cross section of the ice (58). The particles in the section where there were elevated concentrations, $431 \mathrm{CE}$, were retrieved from the meltwater sample that was contiguously collected and span approximately 2.5 years.

TUNU2013 glass compositions: Major element geochemical compositions of tephra shards (sample QUB-1983) in the TUNU2013 ice core at 431 CE were determined using a JEOL 6500F field emission gun scanning electron microscope at Queen's University Belfast. An accelerating voltage of $15 \mathrm{kV}$ was used and the beam was set to $5 \mathrm{nA}$ and rastered over a $5 \times 5 \mu \mathrm{m}$ area. The $\mathrm{Na}, \mathrm{Mg}, \mathrm{Mn}$ and Ti were analyzed using a wavelength dispersive spectrometer (WDS), while the $\mathrm{Si}, \mathrm{Al}, \mathrm{Fe}, \mathrm{K}, \mathrm{Ca}$ and $\mathrm{Cl}$ were collected using the energy dispersive spectrometer. The count times 
on peak for all elements analyzed using WDS was 20s, while Na was collected for 10 s (59). Reference glasses run with the glass shards are included in the SI data.

\section{Acknowledgments}

Fieldwork in El Salvador was funded by a grant awarded to GJAD (CONACYT-CB grant 240447), and we acknowledge the support of MARN-EI Salvador and PNC-EI Salvador. VS and ISP acknowledge funding from a NERC grant (NE/5009035/1). AC acknowledges the Ministero dell'Istruzione dell'Università e della Ricerca project Ash-RESILIENCE. AS and MD acknowledge funding from the ERC (ECHOES, grant 714679). MS acknowledges funding from the European Research Council (ERC) under the European Union's Horizon 2020 research and innovation programme (grant agreement No 820047). DP acknowledges support from a Juan de la Cierva (IJCl-2016-30482) grant. The collection and analysis of the TUNU2013 core was supported by an NSF-PLR grant (\#1204176) to JRM. We thank Walter Hernandez (Ministerio de Medio Ambiente y Recursos Naturales, San Salvador) for assistance in the field, Stephen Harris (Department of Plant Sciences, University of Oxford) for identifying the species of the tree that we radiocarbon dated, and lan Cartwright (School of Archaeology, University of Oxford) for photographing the cross section of the tree. The meteorological data (ERA-Interim) were provided by European Center for Medium-Range Weather Forecasts (ECMWF). We thank three anonymous reviewers and the handling editor, Michael Manga, for their detailed reviews and constructive comments.

\section{References}

1. C. G. Newhall, S. Self, The Volcanic Explosivity Index (VEI): an estimate of explosive magnitude for historical volcanism. J Geophys Res 87, 1231-1238 (1982).

2. M. P. McCormick, L.W. Thomason, C.R. Trepte, Atmospheric Effects of the Mt-Pinatubo Eruption. Nature 373, 399-404 (1995).

3. M. Fujiwara et al., Global temperature response to the major volcanic eruptions in multiple reanalysis data sets. Atmos Chem Phys 15, 13507-13518 (2015).

4. C. Oppenheimer, Ice core and palaeoclimatic evidence for the timing and nature of the great mid-13th century volcanic eruption. Int J Climatol 23, 417-426 (2003).

5. C. Oppenheimer, Eruption politics. Nature Geosci 8, 244-245 (2015).

6. P. Sheets, "Introduction" in Archaeology and Volcanism in Central America, P. D. Sheets, Eds (University of Texas Press, 1983), pp. 1-13.

7. S. Shibata, S. Kitamura, A. Ichikawa, A. "Reconsideración del fechamiento de TBJ desde el punto de vista estratigráfico" in En XXIII Simposio de Investigaciones Arqueológicas en Guatemala, B. Arroyo, A. Linares, L. Paiz, Eds (Museo Nacional de Arqueología y Etnología, Guatemala, 2010), pp. 826-838.

8. D. J. Kennett et al., Development and disintegration of Maya political systems in response to climate change. Science 338, 788-791 (2012).

9. J. Lexa, J. Sebesta, J.A. Chavez, W. Hernandez, Z. Pecskay, Geology and volcanic evolution in the southern part of the San Salvador Metropolitan Area. J Geosci 56, 106140 (2011).

10.I. Suñe-Puchol et al., The Ilopango caldera complex, El Salvador: Origin and early ignimbrite-forming eruptions of a graben/pull-apart caldera structure. J Volcanol Geoth Res 371, 1-19 (2019).

11.C. U. Hammer, H. B. Clausen, W. Dansgaard, Greenland Ice-Sheet Evidence of PostGlacial Volcanism and Its Climatic Impact. Nature 288, 230-235 (1980). 
12. F. Lavigne et al., Source of the great AD 1257 mystery eruption unveiled, Samalas volcano, Rinjani Volcanic Complex, Indonesia. Proc Natl Acad Sci USA 110, 16742-16747 (2013).

13. M. Sigl et al., Timing and climate forcing of volcanic eruptions for the past 2,500 years. Nature 523, 543-549 (2015).

14. R. A. Dull et al., Radiocarbon and geologic evidence reveal llopango volcano as source of the colossal 'mystery' eruption of 539/40 CE. Quat Sci Rev 222, 105855 (2019).

15. H. Earnest, A Reappraisal of the Ilopango Volcanic Eruption in Central El Salvador (Harvard University, 1999).

16.S. J. Johnsen et al., Oxygen isotope and palaeotemperature records from six Greenland ice-core stations: Camp Century, Dye-3, GRIP, GISP2, Renland and NorthGRIP. J Quat Sci 16, 299-307 (2001).

17. H. Williams, H. Meyer-Abich, Volcanism in the Southern Part of El Salvador: With Particular Reference to the Collapse Basins of Lakes Coatepeque and Ilopango (University of California Press, 1955).

18. W. J. Hart, V. Steen-McIntyre, "Tierra Blanca Joven Tephra from the AD 260 eruption of llopango caldera" in Archeology and Volcanism in Central America (University of Texas Press, 1983), pp. 15-34.

19. D. Pedrazzi, et al., The llopango Tierra Blanca Joven (TBJ) eruption, El Salvador: Volcanostratigraphy and physical characterization of the major Holocene event of Central America. J Volcanol Geoth Res 377, 1-22 (2019).

20. H. Neff, P. Sheets, P. "Archaeological applications of tephra analysis by LA-ICP-MS" in Laser Ablation-ICP-MS in Archaeological Research, R.J. Speakman, H. Neff, Eds (University of New Mexico Press, 2005), pp. 117-124.

21. A. Folch, A. Costa, G. Macedonio, FALL3D: a computational model for transport and deposition of volcanic ash. Comput Geosci 35, 1334-1342 (2009).

22. A. Costa et al., Quantifying volcanic ash dispersal and impact of the Campanian Ignimbrite super-eruption. Geophys Res Lett 39, L10310 (2012).

23. A. Costa, V.C. Smith, G. Macedonio, N.E. Matthews, The magnitude and impact of the Youngest Toba Tuff super-eruption. Front Earth Sci 2, 16 (2014).

24. A. Costa, A. Folch, G. Macedonio, Density-driven transport in the umbrella region of volcanic clouds: implications for tephra dispersion models. Geophys Res Lett 40, 48234827 (2013).

25. M. Poret, A. Costa, A. Folch, A. Martí, A., Modelling tephra dispersal and ash aggregation: The $26^{\text {th }}$ April 1979 eruption, La Soufrière St. Vincent. J Volcanol Geoth Res 347, 207-220 (2017).

26. P.J. Reimer et al., IntCal13 and Marine13 Radiocarbon Age Calibration Curves 0-50,000 Years cal BP. Radiocarbon 55, 1869-1887 (2013).

27.C. Bronk Ramsey, Dealing with outliers and offsets in radiocarbon dating. Radiocarbon 51, 1023-1045 (2009).

28. C. Bronk Ramsey, Methods for Summarizing Radiocarbon Datasets. Radiocarbon 59, 1809-1833 (2017).

29. A.G. Hogg et al., SHCal13 Southern Hemisphere Calibration, 0-50,000 Years Cal BP. Radiocarbon 55, 1889-1903 (2013).

30. Q. Hua, M. Barbetti, A.Z. Rakowski, Atmospheric Radiocarbon for the Period 1950-2010. Radiocarbon 55, 2059-2072 (2013). 
31. E.J. Marsh et al., IntCal, SHCal, or a Mixed Curve? Choosing a ${ }^{14} \mathrm{C}$ Calibration Curve for Archaeological and Paleoenvironmental Records from Tropical South America. Radiocarbon 60, 925-940 (2018).

32. L. Marshall et al., Multi-model comparison of the volcanic sulfate deposition from the 1815 eruption of Mt. Tambora. Atmos Chem Phys 18, 2307-2328 (2018).

33. M. Toohey, M. Sigl, Ice core-inferred volcanic stratospheric sulfur injection from 500 BCE to 1900 CE. Earth Syst Sci Data 9, 809-831 (2017).

34.B.G. Koffman, K.J. Kreutz, A.V. Kurbatov, N.W. Dunbar, Impact of known local and tropical volcanic eruptions of the past millennium on the WAIS Divide microparticle record. Geophys Res Lett 40, 4712-4716 (2013).

35. J. Cole-Dai et al., Cold decade (AD 1810-1819) caused by Tambora (1815) and another (1809) stratospheric volcanic eruption. Geophys Res Lett 36 (2009).

36.A. J. Bourne et al., Underestimated risks of recurrent long-range ash dispersal from northern Pacific Arc volcanoes. Sci Rep 6, 29837 (2016).

37. C. Sun et al., Ash from Changbaishan Millennium eruption recorded in Greenland ice: Implications for determining the eruption's timing and impact. Geophys Res Lett 41, 694-701 (2014).

38. C. T. Plummer et al., An independently dated 2000-yr volcanic record from Law Dome, East Antarctica, including a new perspective on the dating of the 1450s CE eruption of Kuwae, Vanuatu. Clim Past 8, 1929-1940 (2012).

39. E. Gautier et al., 2600-years of stratospheric volcanism through sulfate isotopes. Nat Commun 10 (2019).

40. M. Sigl et al., Insights from Antarctica on volcanic forcing during the Common Era. Nat Clim Change 4, 693-697 (2014).

41. L. J. Lucke, G. C. Hegerl, A. Schurer, R. Wilson, Effects of Memory Biases on Variability of Temperature Reconstructions. J Climate 32, 8713-8731 (2019).

42. F. Zhu, J. Emile-Geay, G. J. Hakim, J. King, K. J. Anchukaitis, Resolving the Differences in the Simulated and Reconstructed Temperature Response to Volcanism. Geophys Res Lett 47, e2019GL086908 (2020)

43. M. Toohey, K. Kruger, C. Timmreck, Volcanic sulfate deposition to Greenland and Antarctica: A modeling sensitivity study. J Geophys Res-Atmos 118, 4788-4800 (2013).

44. L. Marshall et al., Exploring How Eruption Source Parameters Affect Volcanic Radiative Forcing Using Statistical Emulation. J Geophys Res-Atmos 124, 964-985 (2019).

45. R. Neukom et al., Inter-hemispheric temperature variability over the past millennium. Nat Clim Change 4, 362-367 (2014).

46.S.E. Metcalfe, J.A. Barron, S.J. Davies, The Holocene history of the North American Monsoon: 'known knowns' and 'known unknowns' in understanding its spatial and temporal complexity. Quat Sci Rev 120, 1-27 (2015).

47.J.W. Webster et al., Stalagmite evidence from Belize indicating significant droughts at the time of Preclassic Abandonment, the Maya Hiatus, and the Classic Maya collapse. Palaeogeogr Palaeod 250, 1-17 (2007).

48. S. Duggen et al., The role of airborne volcanic ash for the surface ocean biogeochemical iron-cycle: a review. Biogeosciences 7, 827-844 (2010).

49.J.F. Luhr, W.G. Melson, "Mineral and glass compositions in June 15, 1991, pumices: Evidence for dynamic disequilibrium in the dacite of Mount Pinatubo" in Fire and Mud: Eruptions and Lahars of Mount Pinatubo, Philippines, C.G. Newhall, Punongbayan, R.S., Eds (University of Washington Press, 1996), pp. 733-750. 
50. J.L. Sarmiento, Atmospheric $\mathrm{CO}_{2}$ stalled. Nature 365, 697-698 (1993).

51.O. Arnalds "The influence of Volcanic Tephra (Ash) on ecosystems" in Advance in Agronomy, D. Sparks, Ed (Elsevier, 2013), pp. 331-380.

52. M. Poret et al., Modeling eruption source parameters by integrating field, ground-based and satellite-based measurements: The case of the 23 February 2013 Etna paroxysm. J Geophys Res-Sol Ea 123, 5427-5450 (2018).

53. I. Aida, Reliability of a tsunami source model derived from fault parameters. $J$ Phys Earth 26, 57-73 (1978).

54. W. Cornell, S. Carey, H. Sigurdsson, Computer simulation of transport and deposition of Campanian Y-5 ash, J Volcanol Geoth Res 17, 89-109 (1983).

55. A. Folch, A. Costa, A. Durant, G. Macedonio, A model for wet aggregation of ash particles in volcanic plumes and clouds: 2. Model application, J Geophys Res 115, B09202 (2010).

56.L. J.Connor, C.B. Connor, "Inversion is the key to dispersion: understanding eruption dynamics by inverting tephra fallout" in Statistics in Volcanology H. M. Mader, S. G. Coles, C. B. Connor, L. J. Connor, Eds (The Geological Society, 2006), pp. 231-242.

57.J.R. McConnell et al., Lead pollution recorded in Greenland ice indicates European emissions tracked plagues, wars, and imperial expansion during antiquity. Proc Natl Acad Sci USA 115, 5726-5731.

58. J. R. McConnell, G.W. Lamorey, S.W. Lambert, K.C. Taylor, Continuous Ice-Core Chemical Analyses Using Inductively Coupled Plasma Mass Spectrometry. Environ Sci Technol 36, 7-11 (2002).

59. S.E. Coulter, J.R. Pilcher, V.A. Hall, G. Plunkett, S.M. Davies, Testing the reliability of the JEOL FEGSEM 6500F electron microprobe for quantitative major element analysis of glass shards from rhyolitic tephra. Boreas 39, 163-169 (2010).

Figure 1. The location of the llopango caldera in El Salvador (red triangle) with the TBJ tephra thicknesses (data from ref. 19 and 20). (A) Tephra thickness $(\mathrm{mm})$ within $\sim 80 \mathrm{~km}$ of the vent. Centimeters of ash were deposited in parts of Mexico (A) while areas closer to the vent (B) were covered with decimeters of ash and PDCs. The tree stump that was radiocarbon dated (Fig. 2) was found within the PDC deposits at the location marked with a black star; and the location of Chalchuapa (El Salvador) is marked by a white star in (B). (C) The TBJ tephra is 20 $\mathrm{cm}$ thick in the Casa Blanca archeological sites in Chalchuapa. (D) The $2 \mathrm{~m}$ thick TBJ deposits $\sim 10 \mathrm{~km}$ west of the vent (grey star in B). Most of the deposit is PDC but there are a few centimeters of fallout at the base, which blankets soil that had been worked by the Maya. (E) The glass shards from the TBJ eruption that were identified in the TUNU2013 ice core from Greenland.

Figure 2. (A) A photograph of the cross section through the Mahogany tree that was felled by the TBJ PDCs and recovered from within the deposits $\sim 25 \mathrm{~km}$ from the volcano (Fig. 1B). Radiocarbon measurements were carried out on samples from two sections (labelled $A$ and $B$ in white) that extend from the pith to the bark edge, and each contiguous sample spans approximately 5 or 10 years (Gap). (B) The radiocarbon data from the samples taken through Section A (bottom) and Section B (top) were modeled onto the IntCal13 radiocarbon calibration curve (26) using a Bayesian statistical approach, which takes into account the order of the dates (older pith at the bottom to bark edge at the top), in OxCal v.4.3.2 (28) to determine calendar dates (Table 1 ). The broader $95.4 \%$ probability distributions are shown in light grey, while the 
68.4\% probability distributions are shown in darker grey. (C) The two determinations of the modeled date at the bark edge (i.e. felling dates in B) were combined in OxCal to provide an eruption date of $425-440$ CE (95.4\% probability).

Figure 3. (A) Ice core non sea-salt sulfur (nssS) data from Greenland (North Greenland Eemian Ice Drilling (NEEM) cores) and Antarctica (West Antarctic Ice Sheet Divide Core (WDS) and the B40 core from Dronning Maud Land), modified from ref. (13). The large volcanic nssS signals (13) are labelled with the calendar year that marks the start of volcanic sulfate deposition. The nssS peaks at 432 CE in Greenland and 434 CE in Antarctica (marked with a double headed arrow) are within the new radiocarbon date range for the TBJ eruption (Fig. 2; Table 1). (B) Particle concentrations and nssS data from the TUNU2013 ice core from Greenland (Fig. 1) spanning 429.5 to $434 \mathrm{CE}$. The peak in particles (solid line $=4.5-9.5 \mu \mathrm{m}$; dashed $=2.4-4.5 \mu \mathrm{m}$ fraction) is centered at $431 \mathrm{CE}$, while the nssS starts to be deposited a year later as it takes longer for it to be deposited from the stratosphere (32). The TUNU2013 glass shards (Fig. 1) that were analyzed (Fig. 5) were extracted from the 431 CE ice sample.

Figure 4. Glass major elements geochemical data from the TBJ deposits (red triangles; data from ref. 19), glass shards from the TUNU2013 ice core located at a depth that corresponds to 431 CE (black squares). Error bars on (A) represent \pm 1 standard deviation of repeat analyses of a reference glass (see SI Appendix), and errors are smaller than the data points on (B). 
Table 1: Radiocarbon determinations of samples taken across sections (A and B) from pith (A4, B4) to the bark edge (A1, B1) of the tree found within the TBJ PDC (see Fig. 2).

\begin{tabular}{|c|c|c|c|c|c|c|c|c|c|c|c|}
\hline $\begin{array}{l}\text { Trunk 1, } \\
\text { Section }\end{array}$ & Sample name & $\begin{array}{c}\text { Lab code } \\
\text { (GrM-) }\end{array}$ & $\% \mathbf{C}$ & $\begin{array}{l}d^{13} C \\
(\% 0)\end{array}$ & \pm & $\begin{array}{c}\text { Acorr } \\
(\%)\end{array}$ & $\pm(1 \sigma)$ & $\begin{array}{c}{ }^{14} \text { C Age } \\
\text { (yr BP) }\end{array}$ & $\begin{array}{c} \pm \\
(1 \sigma)\end{array}$ & \multicolumn{2}{|c|}{$\begin{array}{l}\text { Modelled } \\
\text { radiocarbon } \\
\text { date (CE) at } \\
95.4 \% \\
\text { probability } \\
\end{array}$} \\
\hline \multirow[t]{6}{*}{$A$} & $\mathrm{~A} 1$ & 15054 & 39.1 & -24.53 & 0.21 & 82.06 & 0.20 & 1588 & 20 & \multirow{2}{*}{425} & \multirow{2}{*}{446} \\
\hline & A1 DUPLICATE & 15055 & 38.1 & -24.60 & 0.21 & 82.01 & 0.19 & 1593 & 19 & & \\
\hline & $\mathrm{A} 2$ & 15056 & 40.4 & -26.15 & 0.21 & 81.67 & 0.19 & 1627 & 19 & 420 & 441 \\
\hline & A3 & 15058 & 39.5 & -27.02 & 0.21 & 81.83 & 0.20 & 1611 & 19 & \multirow{2}{*}{400} & \multirow{2}{*}{421} \\
\hline & A3 DUPLICATE & 15060 & 40.9 & -27.20 & 0.21 & 81.80 & 0.21 & 1614 & 20 & & \\
\hline & A4 & 15061 & 39.8 & -27.26 & 0.21 & 81.51 & 0.20 & 1642 & 20 & 390 & 411 \\
\hline \multirow[t]{5}{*}{$B$} & B1 & 15063 & 38.7 & -25.32 & 0.21 & 81.75 & 0.20 & 1618 & 20 & 413 & 435 \\
\hline & B2 & 15196 & 38.8 & -26.27 & 0.21 & 81.79 & 0.20 & 1615 & 19 & \multirow{2}{*}{403} & \multirow{2}{*}{425} \\
\hline & B2 DUPLICATE & 15197 & 38.7 & -26.85 & 0.26 & 81.69 & 0.20 & 1624 & 19 & & \\
\hline & B3 & 15198 & 38.5 & -27.24 & 0.26 & 81.46 & 0.20 & 1647 & 19 & 393 & 415 \\
\hline & B4 & 15200 & 37.5 & -26.89 & 0.26 & 81.51 & 0.20 & 1642 & 19 & 383 & 405 \\
\hline
\end{tabular}

Note: Duplicate analyses were combined in the OxCal model. 
Table 2: Major element compositions (normalized to 100\%) of glass shards in the TUNU2013 ice core (Greenland) at 431 CE compared to those in the TBJ eruption deposits

\begin{tabular}{|c|c|c|c|c|c|c|c|c|c|c|c|c|}
\hline & $\mathrm{SiO}_{2}$ & $\mathrm{TiO}_{2}$ & $\mathrm{Al}_{2} \mathrm{O}_{3}$ & FeOt & MnO & $\mathrm{MgO}$ & $\mathrm{CaO}$ & $\mathrm{Na}_{2} \mathrm{O}$ & $\mathrm{K}_{2} \mathrm{O}$ & $\mathrm{Cl}$ & $\begin{array}{r}\text { Analytical } \\
\text { total }\end{array}$ & $n^{\wedge}$ \\
\hline \multicolumn{13}{|c|}{ TUNU2013, $431 \mathrm{CE}$} \\
\hline QUB-1983-2 & 76.39 & 0.27 & 13.17 & 1.06 & 0.06 & 0.30 & 1.18 & 4.42 & 3.00 & 0.15 & 96.96 & \\
\hline QUB-1983-10 & 76.22 & 0.29 & 13.30 & 0.95 & 0.06 & 0.31 & 1.23 & 4.42 & 3.00 & 0.21 & 95.43 & \\
\hline QUB-1983-3 & 76.80 & 0.18 & 13.19 & 1.19 & 0.12 & 0.28 & 1.18 & 3.66 & 3.05 & 0.34 & 91.25 & \\
\hline QUB-1983-4 & 76.08 & 0.21 & 13.37 & 1.06 & -0.05 & 0.23 & 1.15 & 4.80 & 2.91 & 0.23 & 97.45 & \\
\hline QUB-1983-4b & 77.19 & 0.35 & 13.02 & 1.03 & 0.00 & 0.27 & 1.25 & 3.49 & 3.19 & 0.21 & 93.93 & \\
\hline QUB-1983-7 & 75.76 & 0.28 & 13.11 & 0.97 & -0.01 & 0.27 & 1.09 & 5.28 & 3.07 & 0.17 & 97.47 & \\
\hline QUB-1983-6 & 75.71 & 0.27 & 12.88 & 1.06 & 0.05 & 0.24 & 1.09 & 5.37 & 3.13 & 0.19 & 96.54 & \\
\hline QUB-1983-2b & 65.48 & 0.73 & 16.14 & 3.81 & 0.23 & 2.27 & 3.50 & 5.78 & 1.87 & 0.20 & 96.48 & \\
\hline \multicolumn{13}{|l|}{ TBJ } \\
\hline \multirow[t]{2}{*}{ Rhyolite* } & 77.14 & 0.19 & 12.75 & 1.19 & 0.07 & 0.20 & 1.23 & 4.36 & 2.87 & 0.20 & & \\
\hline & 0.46 & 0.03 & 0.34 & 0.10 & 0.04 & 0.03 & 0.09 & 0.20 & 0.12 & 0.02 & & 248 \\
\hline \multicolumn{13}{|c|}{ Representative analyses of the less evolved TBJ glasses } \\
\hline ILO-32_dark-38 & 58.96 & 0.65 & 12.61 & 7.15 & 0.26 & 6.62 & 9.54 & 3.07 & 0.97 & 0.09 & 96.10 & \\
\hline ILO-32_grey-2 & 65.55 & 0.49 & 15.60 & 4.58 & 0.20 & 2.63 & 5.09 & 3.82 & 1.68 & 0.17 & 92.68 & \\
\hline ILO-32_grey-13 & 68.56 & 0.53 & 15.90 & 3.28 & 0.16 & 0.83 & 3.54 & 4.64 & 2.18 & 0.14 & 92.68 & \\
\hline
\end{tabular}

*average composition of the rhyolite population (Pedrazzi et al., 2019) with ${ }^{\wedge} n$ for $\mathrm{Cl}=150$. Analytical total is the original unnormalized value. Reference glass analyses are included in the Supporting Information. 

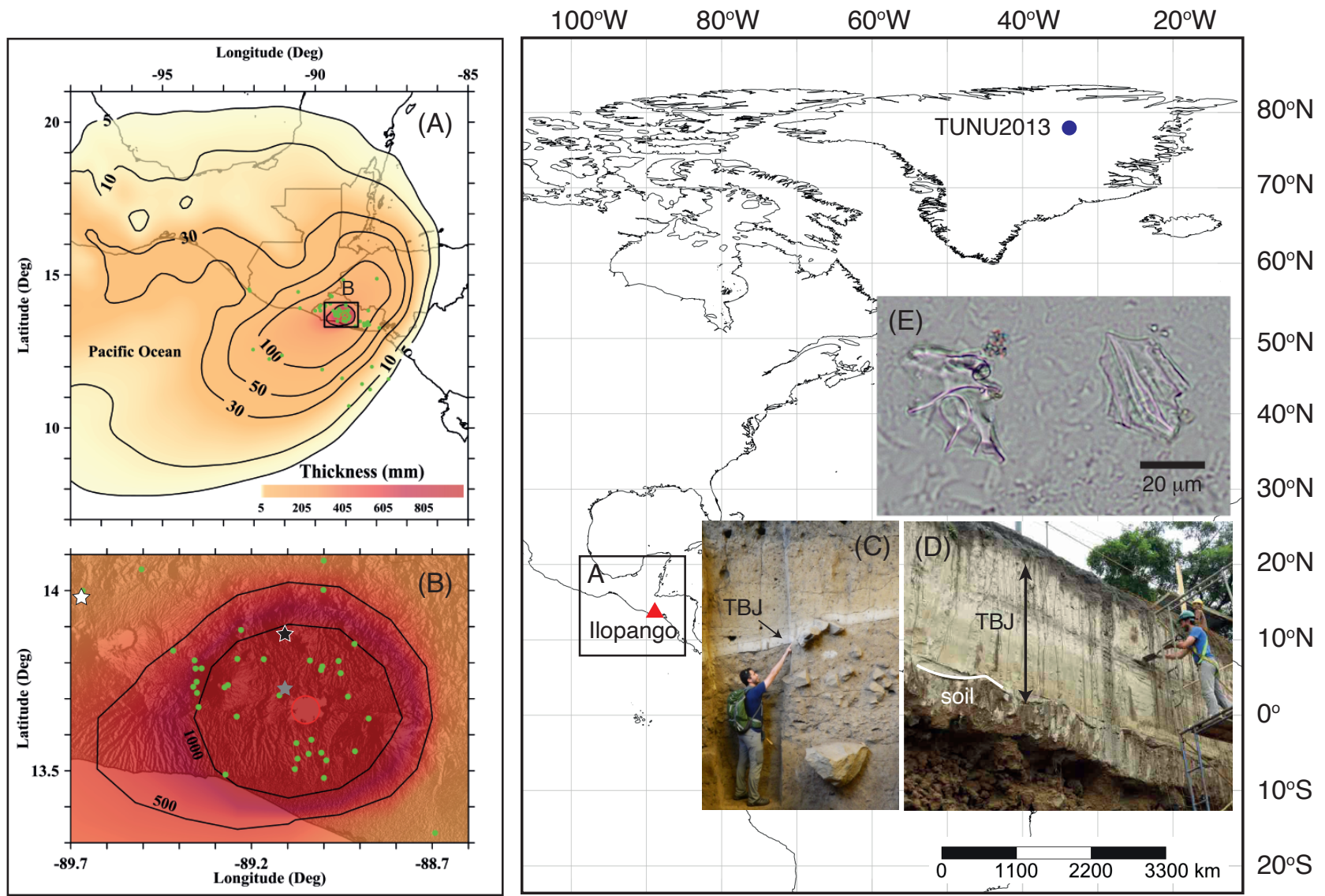

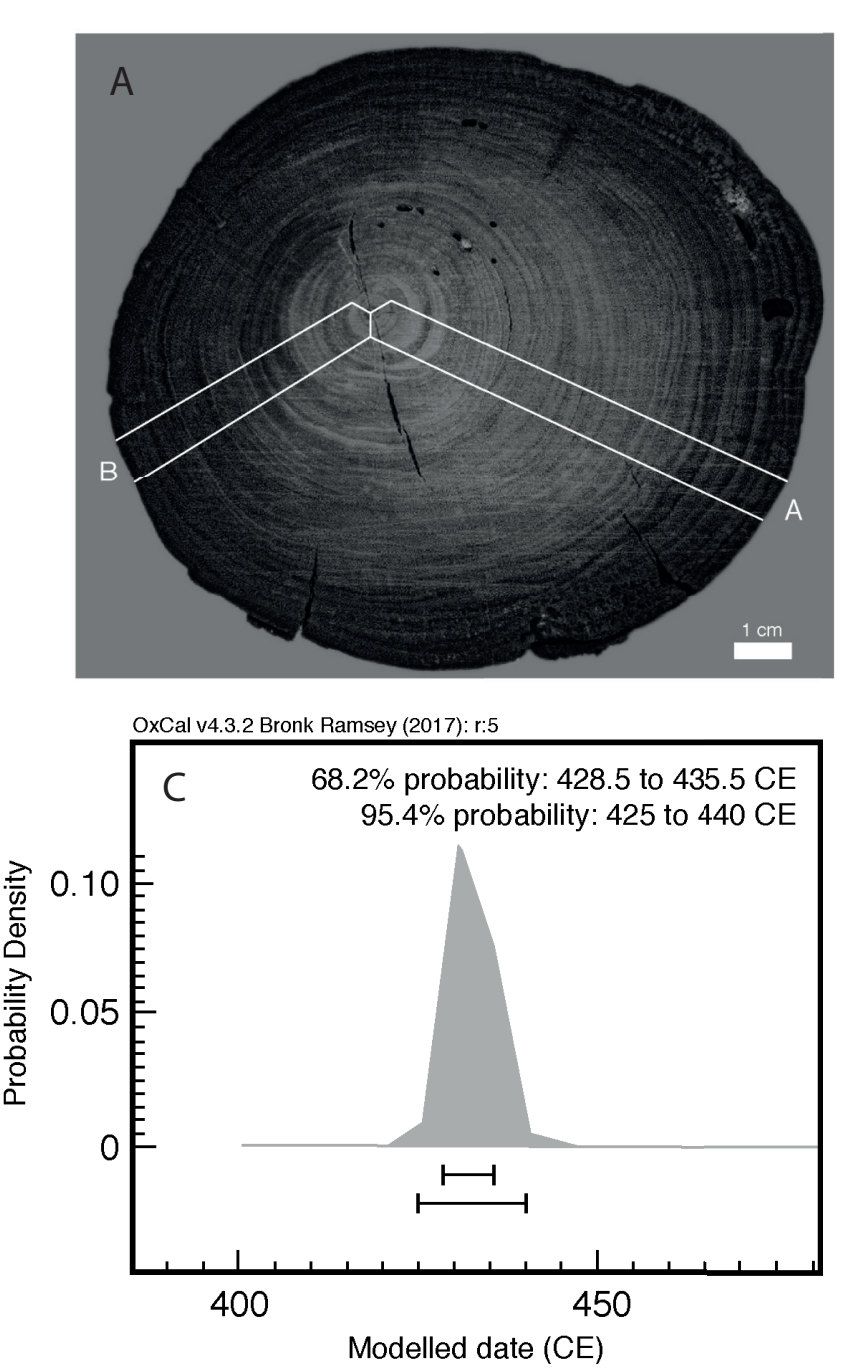

O.Cal v4.3.2. Bronk Ramsery (2017); r.5 IntCal13 atmospheric Cunve (Reimer et al 2013)

Boundary

Felling- $B$

Gap 5

R Date B1-15063

Gap 10

R_Combine B2

Gap 10

R_Date B3-15198

Gap 10

R_Date B4-15200

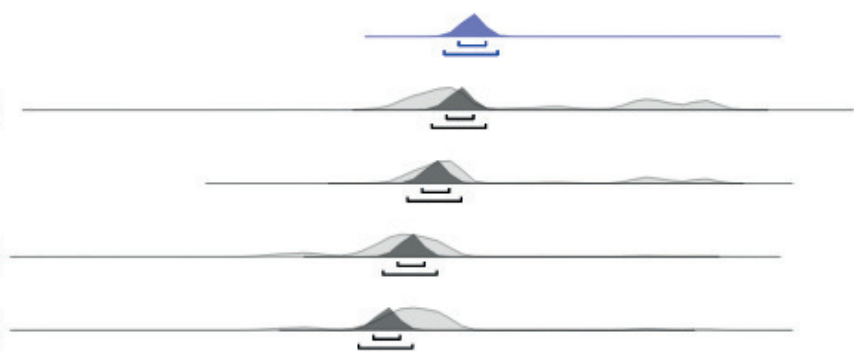

Boundary Centre

D_Sequence Trunk 1-Section B

\section{Boundary}

Felling- $A$

Gap 5

R Combine $A 1$

Gap 10

R_Date A2-15056

Gap 10

R_Combine $A 3$

Gap 10

R_Date A4-15061

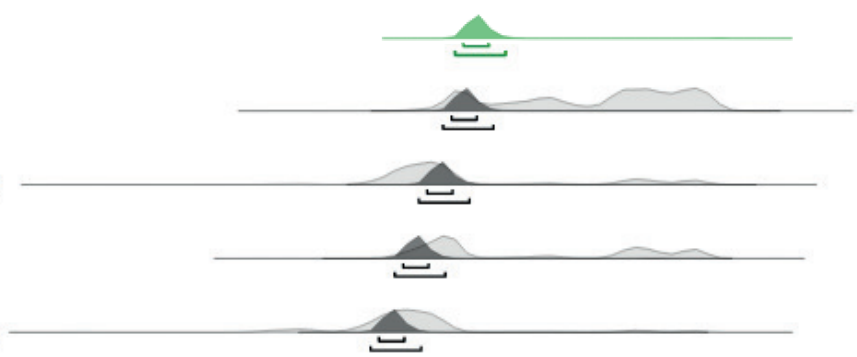

Boundary Centre

D_Sequence Trunk 1-Section A

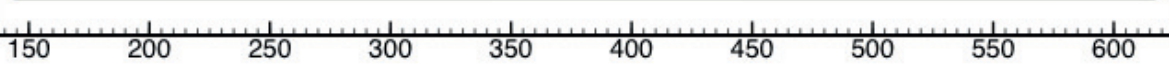



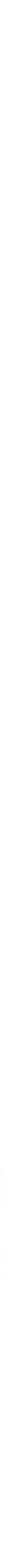

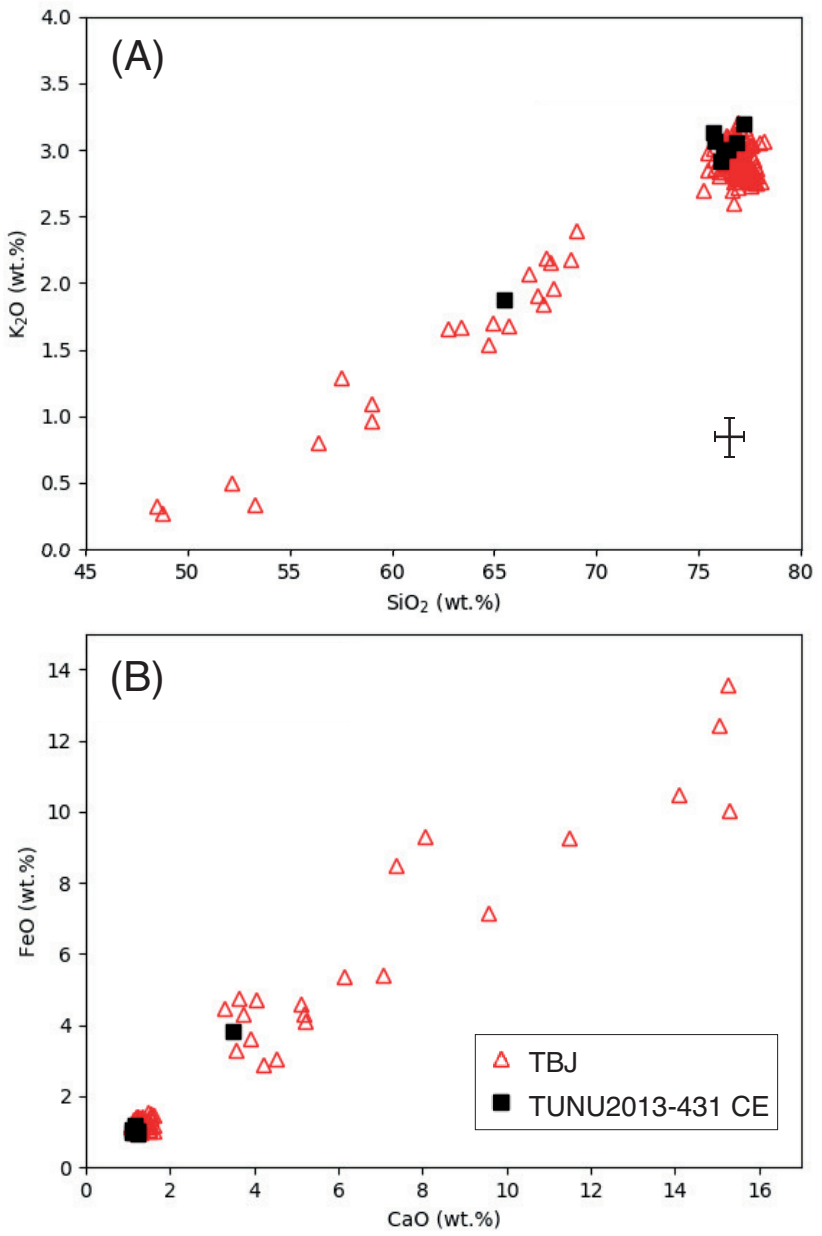